\title{
Can Phototherapy Requirements Be Predicted through Cord Blood Test Results in Newborns?
}

\begin{tabular}{|c|c|c|}
\hline Author(s) & \multicolumn{2}{|l|}{ (i) Berna Hekimoğlu } \\
\hline Affiliation(s) & \multicolumn{2}{|c|}{ Health Science University, Kanuni Education and Research Hospital, Trabzon, Turkey } \\
\hline $\begin{array}{c}\text { Article } \\
\text { Information }\end{array}$ & $\begin{array}{l}\text { Article Type: Original Articles } \\
\text { Article Group: Newborn }\end{array}$ & $\begin{array}{l}\text { Received: } 17.10 .2020 \\
\text { Accepted: } 08.12 .2020 \\
\text { Available Online: } 27.12 .2020\end{array}$ \\
\hline
\end{tabular}

Cite this article as: Hekimoğlu B. Can Phototherapy Requirements Be Predicted through Cord Blood Test Results in Newborns? J Pediatr Acad 2020; 1: 99-102.

\section{Abstract}

Hyperbilirubinemia is one of the common problems in newborns. If not diagnosed and treated in time, high bilirubin levels can cause kernicterus and permanent brain damage. Therefore, early detection of hyperbilirubinemia development risk in newborns is important. In this study, we aimed to investigate whether the direct Coomb'test and cord blood bilirubin level (UCB) could be used to predict newborns at a high risk of developing hyperbilirubinemia.A total of 300 newborns born between January-June 2014 with a birth weight $\geq 2500 \mathrm{~g}$ and gestational week $\geq 37$ weeks were included in the study. The results of direct Coombs'test, UCB, maternal and infant blood groups and serum total bilirubin levels were analyzed retrospectively.Phototherapy was given to $35(11.7 \%)$ of 300 newborns and $25(8.3 \%)$ had positive direct Coombs'test. ABO incompatibility was found in the etiology of $51.5 \%$ of the cases with hyperbilirubinemia. It has been observed that patients with positive direct Coombs'test have a high rate of hospitalization $(p<0.001)$. The UCB levels were found to be statistically higher in cases who received phototherapy $(2.7 \pm 1.0$ and $1.8 \pm 0.6$, respectively, $p<0.01)$. The cutoff value of UCB for predicting the occurrence of significant hyperbilirubinemia requiring phototherapy was $2.0 \mathrm{mg} / \mathrm{dL}$, with a sensitivity of $77 \%$ and specificity of $77 \%$ and negative predictive value was $96 \%$. The UCB and direct Coombs'test could be useful in predicting the possibility of significant hyperbilirubinemia and hospitalization in newborns. Thus, detection of newborns at risk of hyperbilirubinemia with a noninvasive method within a few hours after birth will prevent early discharge and provide close follow-up and early treatment.

Keywords: Cord blood bilirubin, direct Coombs'test, hyperbilirubinemia, newborn

Correspondence: Berna Hekimoglu, Department of Neonatology, Health Science University, Kanuni Education and Research Hospital, Trabzon, Turkey

E-mail: dr.bernasygn@gmail.com 


\section{Introduction}

Hyperbilirubinemia is one of the common problems in newborns. If not diagnosed and treated in time, high bilirubin levels can cause kernicterus and permanent brain damage. ${ }^{1}$ Therefore, early detection of hyperbilirubinemia development risk in newborns is important. In developed countries, the incidence of neonatal hyperbilirubinemia has been reported as 1745 and 2-36 cases per 100,000 live births for serum bilirubin levels $>25 \mathrm{mg} / \mathrm{dl}$ and $30 \mathrm{mg} / \mathrm{dl}$, respectively. ${ }^{2,3}$ In our country, in a multicenter study published in 2018, the incidence of severe hyperbilirubinemia $(>25 \mathrm{mg} / \mathrm{dl})$ and bilirubin encephalopathy has been reported as $6.4 \%$ and $2.3 \%$, respectively. ${ }^{4}$ The gold standard to measure hyperbilirubinemia continues to be only total serum bilirubin. This technique is painful and can cause anemia if applied frequently. Therefore, we aimed to investigate whether the direct Coomb'test and cord blood bilirubin level (UCB) could be used to predict newborns at a high risk of developing hyperbilirubinemia.

\section{Material and Method}

This study was conducted by retrospective analysis of clinical and laboratory data in Ordu University Medical Faculty, Clinic of Obstetrics and Gynecology and medical records of the infants admitted to the neonatal intensive care unit between January and June 2014. A total of 300 babies with a birth weight $\geq 2500 \mathrm{~g}$ and gestational week $\geq 37$ weeks were included in the study. In accordance with the policy of our hospital, total bilirubin levels, blood groups and direct Coombs'test are routinely studied from umbilical cord blood in order to evaluate the risk of blood group incompatibility in all infants who are born in our hospital. In addition, serum total bilirubin levels of those who were hospitalized for phototherapy treatment in the first 24 hours were recorded retrospectively. The infants who received phototherapy treatment in the first 24 hours of life were considered as Group 1, and those who were not given phototherapy treatment were considered as Group 2. Phototherapy indication was evaluated in accordance with the recommendations of the American
Academy of Pediatrics (AAP). ${ }^{5}$ Prematurity, those with 1 and 5 minutes of Apgar score $<7$, those with congenital anomalies, cases with complications that aggravate the development of hyperbilirubinemia such as sepsis or hematoma were not included in the study.

Demographic features, UCB and direct Coombs' test values were compared between the two groups. The UCB levels were determined using the Beckman Coulter Au2700. Direct Coombs'test was performed through full automatic gel centrifugation method. Total serum bilirubin levels were determined on heel stick (capillary) samples using bedside BR $5000 \mathrm{~N}$ Apel bilirubinometer. This study was approved by Local ethics committee was approved this study with the number of 15.05.2016-120.

\section{Statistical analysis}

Statistical analysis was performed using SPSS version 13.0 package software (SPSS for Windows Version 13.0. SPSS Inc. Chicago, USA, Released 2005). Descriptive statistical analysis was carried out for all variables. The results are expressed as mean \pm standard deviation. Chi-square test was used in the comparison of categorical variables. Normality of the variables was tested using Kolmogorov-Smirnov and Shapiro-Wilk tests. Nonnormally distributed variables between two groups were analyzed using Mann-Whitney U test. ROC curve test was used to determine cutoff values of UCB in infants who required phototherapy. Sensitivity, specificity, negative predictive value and positive predictive value were calculated.

\section{Results}

A total of 300 newborns were included in the study. There were $35(11.7 \%)$ cases in Group 1 and 275 cases in Group 2 (88.3\%). Direct Coombs'test was positive in $25(8.3 \%)$ of all cases.

Demographic features, direct Coombs'test and UCB values were compared between the two groups (Table $1)$.

\begin{tabular}{|c|c|c|c|}
\hline & Grup 1 & Grup 2 & $\mathbf{P}$ \\
\hline Gestationalage (weeks) & $39.2 \pm 0.9$ & $38.9 \pm 1.2$ & 0.12 \\
\hline Birth weight $(\mathrm{g})$ & $3364.7 \pm 359.5$ & $3251.1 \pm 401.7$ & 0.09 \\
\hline Male gender $[\%,(n)]$ & $46(16)$ & $50(133)$ & 0.62 \\
\hline Vaginal delivery $[\%,(n)]$ & $40(14)$ & $50(133)$ & 0.26 \\
\hline Blood type incompatibility [\%, (n)] & $83(29)$ & $23(60)$ & 0.62 \\
\hline ABO inconsistency $[\%,(n)]$ & $52(18)$ & $14(36)$ & $<0.001$ \\
\hline $\mathrm{ABO}+\mathrm{Rh}$ inconsistency $[\%,(\mathrm{n})]$ & $11(4)$ & $1(3)$ & $<0.001$ \\
\hline Direct Coombs test $[\%,(n)]$ & $57(20)$ & $2(5)$ & $<0.001$ \\
\hline UCB levels $(\mathrm{mg} / \mathrm{dl})^{*}$ & $2.7 \pm 1.0$ & $1.8 \pm 0.6$ & $<0.001$ \\
\hline
\end{tabular}


In the etiology of the cases with direct Coombs'test results; $\mathrm{ABO}$ incompatibility, Rh incompatibility, both $\mathrm{ABO}$ and $\mathrm{Rh}$ incompatibility were found in $52 \%$ ( $\mathrm{n}: 13), 20 \%$ (n: 5), $8 \%(n: 2)$ respectively, while the cause could not be determined in $20 \%$ of the cases. The mean bilirubin level of the patients was $8.6 \pm 2.4 \mathrm{mg} / \mathrm{dl}$. Intravenous immunoglobulin was given to 2 cases $(5.7 \%)$ since bilirubin values were close to the blood exchange limit.

The rate of hospitalization and early phototherapy initiation rate were found to be statistically significantly higher in cases with positive direct Coombs'test compared to negative ones $(p<0.001)$. In 20 of 25 patients who were positive for direct Coombs'test in the first 24 hours, phototherapy was initiated by finding serum bilirubin levels above the 95th percentile according to the bilirubin normogram for age. It was found that UCB levels had higher in Group 1 compared to Group $2(2.7 \pm 1.0$ and $1.8 \pm 0.6$, respectively, $p<0.001)$. Patients with positive direct Coombs'test had higher UCB levels than those with negative ones $(3.1 \pm 0.9$ and $1.8 \pm 0.6$, respectively, $\mathrm{p}<0.001)$. When cutoff value for UCB was taken as $2.0 \mathrm{mg} / \mathrm{dl}$; sensitivity, specificity, positive predictive value and negative predictive value were found to be $77 \%$, $77 \%, 96 \%$ and $31 \%$, respectively. (Figure 1)

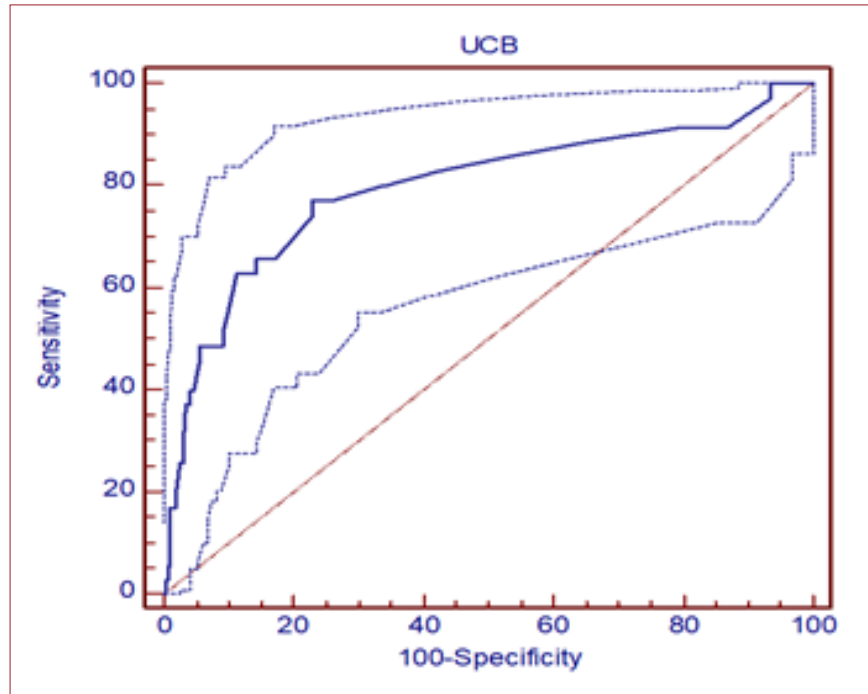

Figure 1. ROC analysis of cord blood bilirubin in determining phototherapy need.

\section{Discussion}

The one of the most frequent cause of readmission to neonatal units is hyperbilirubinemia. In the etiology of newborns hospitalized with the diagnosis of indirect hyperbilirubinemia, blood group incompatibility has been reported most frequently. ${ }^{6}$ In the study of Yigit et al. $^{7}$ it was reported that $21 \%$ of the cases had $A B O$ incompatibility and $4.7 \%$ of them had Rh incompatibility, while in the study of Bolat et al. ${ }^{8} 30.2 \%$ of the cases had $\mathrm{ABO}$ incompatibility and $7.7 \%$ of them had $\mathrm{Rh}$ incompatibility. In our study, $12 \%$ of the cases were hospitalized due to significant hyperbilirubinemia within the first 24 hours after birth, and similar to the literature, mostly $A B O$ incompatibility was found in the etiology of hyperbilirubinemia.
The direct Coombs'test is an important test in the differential diagnosis of indirect hyperbilirubinemia and hemolytic disease of the newborn. It has been reported that the incidence of direct Coombs'test positivity is 1-9\% in newborns. ${ }^{9}$ In our study, the direct Coombs'test positivity rate was $8.3 \%$. $\mathrm{ABO}$ incompatibility was the most common in the etiology of cases with positive direct Coombs'test.

There are many studies in the literature investigating the relationship between direct Coombs' test positivity and phototherapy. In a study conducted by Madan et al. ${ }^{10}$ it was reported that babies with a positive direct Coombs'test were not more likely to go back to the hospital for phototherapy than those who were negative. They also emphasized that it is not necessary to routinely perform a direct Combs'test from cord blood in newborns. Procianoy ${ }^{11}$ and Schonitzer ${ }^{12}$ reported that if the direct Coombs'test is used in combination with UCB, newborns with a high risk of developing hyperbilirubinemia can be detected earlier. On the other hand, there are studies reporting that the bilirubin level in cord blood alone is more determinative and sufficient in determining the risk of developing hyperbilirubinemia. ${ }^{13}$ The results in our study show that newborns with positive direct Coombs'test have higher UCB levels than those who are negative, and they need more phototherapy. Our results support the hypothesis that cord blood direct Coombs'test results are useful in early detection of cases with high risk of developing hyperbilirubinemia. It has also been shown that patients who are positive for direct Coombs'test results should be followed up more closely.

Rosenfeld ${ }^{14}$ and Knudsen ${ }^{15}$ reported that the high UCB level can be used to identify newborns with a risk of development severe hyperbilirubinemia. Rosenfeld et al. ${ }^{14}$ reported that the risk of developing hyperbilirubinemia would be high when the UCB level was $>2.0 \mathrm{mg} / \mathrm{dl}$. In the study of Knudsen et al. ${ }^{15}$ this level was reported as $>2.35$ $\mathrm{mg} / \mathrm{dl}$. Knüpfer et al. ${ }^{16}$ it was reported that $70.3 \%$ sensitivity and $65.6 \%$ negative predictive value for the UCB level of $1.76 \mathrm{mg} / \mathrm{dl}$. In the study of Ipek et al. ${ }^{17}$ it was reported that the sensitivity was $50 \%$ and the negative predictive value was $97.9 \%$ for the UCB of $2.60 \mathrm{mg} / \mathrm{dl}$. In the study of Aktas et al. ${ }^{18}$ it was reported that the sensitivity was $82 \%$, and specificity of $99 \%$ for the UCB of $1.67 \mathrm{mg} / \mathrm{dl}$. The fact that different cutoff levels were determined in all these studies may be due to the heterogeneity of the study groups. This situation prevents the standard use of the test. Therefore, we aimed to determine the cutoff value of UCB level in order to predict babies who may be developed significant hyperbilirubinemia. In our study when cutoff value for $U C B$ was taken as $2.0 \mathrm{mg} / \mathrm{dl}$ sensitivity, specificity, positive predictive value and negative predictive value were found to be $77 \%, 77 \%, 96 \%$ and $31 \%$, respectively. The high negative predictive value of the test indicates that the risk of developing severe hyperbilirubinemia is low in cases with UCB $<2 \mathrm{mg} / \mathrm{dl}$. In cases with UCB level $>2 \mathrm{mg} / \mathrm{dl}$, the possibility of predicting the possibility of significant hyperbilirubinemia and hospitalization will be higher when the evaluation is made together with the direct Coombs'test. This situation is important not only to protect infants against kernicterus, but also to early refer infants from the peripheral centers to tertiary referral hospitals. 


\section{Conclusion}

To summarize, nowadays, there is no exact method for the prevention of jaundice in newborns with risk factors. Our results suggest that the evaluation of UCB level and direct Coombs'test are a useful indicator for developing significant hyperbilirubinemia in healthy term newborns. It may help us to determine infants at high and low risks. Thus, detection infants of with high risk with a non-invasive method within a few hours after birth will prevent early discharge and provide close follow-up and early treatment.

Acknowledgements: This study was accepted as an oral poster the $6^{\text {th }}$ Anniversary Meeting of the EPA, February 27-29 2020, Kayseri

Conflict of Interest Statement: Author declares that she has not received any financial support or other benefits from commercial sources for the work described in this paper. She also declares that she has no other financial interests that could create a potential conflict of interest or the appearance of a conflict of interest with regard to this work.

Ethics Committee Approval: Local ethics committee was approved this study with the number of 15.05.2016120.

Financial Disclosure: The author declared that this study has received no financial support.

Informed Consent: Because the study was designed retrospectively, no written informed consent form was obtained from patients.

Peer-review: Externally peer-reviewed.

\section{References}

1. Maisels MJ. Neonatal hyperbilirubinemia and kernicterus - not gone but sometimes forgotten. Early Hum Dev. 2009;85:727-732. [CrossRef]

2. Kaplan M, Bromiker R, Hammerman C. Severe neonata hyperbilirubinemia and kernicterus: are these still problems in the third millennium?. Neonatology. 2011;100:354-362. [CrossRef]

3. Johnson L, Bhutani VK, Karp K, Sivieri EM, Shapiro SM. Clinical report from the pilot USA Kernicterus Registry (1992 to 2004). J Perinatol. 2009;29:S25-S45. [CrossRef]
4. Erdeve O, Okulu E, Olukman O, et al. The Turkish Neonatal Jaundice Online Registry: A national root cause analysis. PLoS One. 2018;13:e0193108. [CrossRef]

5. American Academy of Pediatrics Subcommittee on Hyperbilirubinemia. Management of hyperbilirubinemia in the newborn infant 35 or more weeks of gestation Pediatrics. 2004;114:297-316. [CrossRef]

6. Yaseen H, Khalaf M, Rashid N, Darwich M. Does prophylactic phototherapy prevent hyperbilirubinemia in neonates with ABO incompatibility and positive Coombs' test?. J Perinatol. 2005;25:590-594. [CrossRef]

7. Yiğit $O$, Sezgin B, Ozgurhan B, et al. İndirekt hiperbilirubinemili olguların değerlendirilmesi. Bakırköy Tıp Dergisi 2006;2:241-246.

8. Bolat $F$, Bülbül $A$, Cömert $S$, et al. Yenidoğan ünitemize indirek hiperbilirubinemi tanısı ile yatırılan term yenidoğan bebeklerin değerlendirilmesi. Çocuk Dergisi. 2010;10:69-74. (in Turkish) [CrossRef]

9. Altuntaş $N$, Çelebi DT, Koçak $M$, et al. Yenidoğan bebeklerde direkt coombs testi taraması ve pozitifliğinin morbidite üzerine etkisi; tek merkez deneyimi. Pam Tıp Derg. 2015;8:39-44. (in Turkish) [CrossRef]

10. Madan A, Huntsinger K, Burgos A, Benitz WE. Readmission for newborn jaundice: the value of the Coombs' test in predicting the need for phototherapy. Clin Pediatr (Phila). 2004;43:63-68. [CrossRef]

11. Procianoy RS, Giacomini CB, Farina DM, et al. Early diagnosis of $\mathrm{ABO}$ hemolytic disease of the newborn. Eur $J$ Pediatr. 1987;146:390-93. [CrossRef]

12. Schönitzer D, Frisch $H$. Frequenz, Laboratoriumsdiagnostik und serologische Voraussage des ABO-bedingten Morbus hämolyticus neonatorum. Padiatr Padol. 1984;19:263-278. (in German) [CrossRef]

13. Leistikow EA, Collin MF, Savastano GD, de Sierra TM, Leistikow BN. Wasted health care dollars. Routine cord blood type and Coombs' testing. Arch Pediatr Adolesc Med. 1995;149:1147-1151. [CrossRef]

14. Rosenfeld J. Umbilical cord bilirubin levels as a predictor of subsequent hyperbilirubinemia. J Fam Pract. 1986;23:556-558.

15. Knudsen A. Prediction of the development of neonatal jaundice by increased umbilical cord blood bilirubin. Acta Paediatr Scand. 1989;78:217-221. [CrossRef]

16. Knüpfer M, Pulzer F, Gebauer C, Robel-Tillig E, Vogtmann C. Predictive value of umbilical cord blood bilirubin for postnata hyperbilirubinaemia. Acta Paediatr. 2005;94:581-587. [CrossRef]

17. Ipek IO, Bozaykut A, Çağrıl SC, Sezer RG. Does cord blood bilirubin level help the physician in the decision of early postnatal discharge?. J Matern Fetal Neonatal Med. 2012;25:1375-1378. [CrossRef]

18. Aktas S, Dogan C, Okmen ZH, Gulec SG. Is Cord Blood Bilirubin Level a Reliable Predictor for Developing Significant Hyperbilirubinemia?. Am J Perinatol. 2019;36:317-321. [CrossRef] 